\title{
A comunicação nos empreendimentos econômicos solidários
}

\author{
Marília Veríssimo Veronese \\ Doutora em Psicologia pela Pontifícia Universidade Católica do Rio Grande do Sul - PUCRS. \\ Professora e pesquisadora integrante do Grupo de Pesquisa em Economia Solidária do \\ Programa de Pós-Graduação em Ciências Sociais, da Universidade do Vale do Rio dos Sinos - \\ Unisinos, em São Leopoldo, Brasil. \\ E-mail:mariliav@unisinos.br \\ Marina Rodrigues Martins \\ Bacharel em Comunicação Social, habilitação em Relações Públicas pela Universidade do Vale do \\ Rio dos Sinos, desde agosto de 2008. Atualmente, realiza intercâmbio de trabalho como assistente \\ de comunicação na instituição jesuita Holy Family Social Services, em Sydney, Australia. \\ E-mail: mrodriguesmartins@gmail.com
}

Resumo: $\mathrm{O}$ artigo apresenta a reflexão sobre o processo da comunicação na prática autogestionária em empreendimentos econômicos solidários. As organizações investigadas localizam-se em São Leopoldo, Rio Grande do Sul, Brasil. Mapearam-se as diferentes formas de participação dos sujeitos envolvidos e como elas implicam nas decisões coletivas. O texto é resultado de duas pesquisas; a primeira, fruto da monografia de curso em Comunicação Social, e a segunda no âmbito da bolsa de iniciação científica PIBIC/ CNPq, no Programa de Pós-Graduação em Ciência Sociais da Unisinos. Foi empregada metodologia qualitativa na coleta e análise dos dados. No processo de conclusão, perceberam-se as representações da autogestão ligadas à autonomia. No entanto, a prática demonstra as dificuldades de exercer o poder compartilhado, potencializadas pelo restrito processo de comunicação.

Palavras-chave: economia solidária, relações públicas, comunicação e autogestão.
Abstract: The article proposes a reflection of the communication process on the practice of self-management in solidary enterprises. The investigated organizations were located in São Leopoldo city, in Southern Brazil. The survey aimed to map the different forms of participation of individuals involved and how it is involved in collective decisions. The text is the result of two researches: the first was made by undergraduates in Social Communication; and the second by research interns in the Graduate Program of Social Science at UNISINOS. Qualitative methodology was used to collect and analyze information. The results showed that the workers have representations of self-management linked to autonomy. However, over the practice were demonstrates the difficulties of exercise the share power and it is powerfully through a limited process of communication.

Keywords: social and solidary economy, public relations, communication and self-management.

O texto contextualiza a comunicação no processo da autogestão, em empreendimentos econômicos solidários (EES), a fim de demonstrar como ela influencia no exercício da participação ativa e do poder compartilhado. 
comunicação \& educação • Ano XV • número 2 • maio/ago 2010

1. MARTINS, Marina Rodrigues. As relações públicas e a economia solidária: um compromisso para transformação social. Monografia apresentada para o Curso de Comunicação Social Habilitação em Relações Públicas, na Universidade do Vale do Rio dos Sinos, 2007. Não publicado.

2. Fonte: Base de Dados consolidada pelo Grupo de Pesquisa em Economia Solidária da Unisinos, jan. 2008. Ligeiras variações podem ocorrer em rela ção aos dados oficiais divulgados pelo Ministério do Trabalho e Emprego.

3. ASSEBURG, Hans Benno; OGANDO, Cláudio Barcelos. Cartilha da Economia Solidária: subsídio informativo. A Economia Solidária no Rio Grande do Sul: resultados do primeiro mapeamento nacional. A perspectiva dos Direitos Humanos. San José/Costa Rica: Unesco, 2006.

4. Ibid

5. Ibid., p. 16.

6. HENRIQUES, Márcio Simeone et al. Relações Públicas em projetos de mobilização social: funções e características. In: HENRIQUES, Márcio Simeone (Org.). Comu nicação e estratégias de mobilização social. 2. ed. São Paulo: Autêntica, 2004. p. 17-32

7. VIEIRA, Roberto Fonseca. Relações Públicas: opção pelo cidadão. Rio de Janeiro: Mauad, 2002

8. ALBUQUERQUE, Paulo Peixoto de. Autogestão. In: CATTANI, Antonio David (Org.). A outra economia. Porto Alegre: Veraz Editores, 2003. p. 20-26.

9. PERUZZO, Cicília Maria Krohling. Comunicação nos movimentos populares: a participação na construção da cidadania. Petrópolis, RJ: Vozes 1998. p. 70.

10. VERONESE, Marília Veríssimo. Representações
Junto a isso, pretende subsidiar o entendimento do processo comunicacional como ferramenta educacional, além da informativa. Para tanto foi observado como as lideranças e trabalhadores associados percebem e conduzem o processo de comunicação, além de como acontecem a democratização da informação e a influência desse andamento nos momentos de decisão. A primeira pesquisa ${ }^{1}$, desenvolvida como acadêmica de comunicação social, e a vivência na assessoria aos EES, incubados pelo Programa Tecnologias Sociais para Empreendimentos Solidários Unisinos, evidenciaram a fragilidade do processo de comunicação nesses grupos. Essa peculiaridade promoveu a continuidade da investigação durante a bolsa de iniciação científica PIBIC/ CNPq, em 2008.

A administração coletiva se configura no âmbito da economia solidária (ecosol), entendida como conjunto de atividades econômicas organizadas e realizadas solidariamente, por meio da associação autogestionária. Atualmente, é possível identificar o considerável número de modelos empresariais nessa perspectiva, gerando $513.466^{2}$ postos de trabalho. A proposta visa transformar o exercício do trabalho em fonte de renda, segurança, liberdade e realização para os trabalhadores e comunidade como um todo ${ }^{3}$. Segundo os autores $^{4}$, a ecosol é formada por EES (associações comunitárias, cooperativas, empresas de autogestão, clubes de troca e demais formas de organização coletiva) que têm como objetivo a fusão entre o ideal da propriedade coletiva, guiado pela autogestão, cooperação e democracia entre os trabalhadores, e o real, como orientador de planos gerenciais autossustentáveis. Ou seja, os EES buscam unir o espírito empresarial e o espírito solidário ${ }^{5}$, a fim de torná-lo gerador de trabalho, renda e cidadania de maneira sustentável. Assim, entende-se que a característica autogestionária potencializa a igualdade e deve ser baseada no exercício do poder compartilhado entre os membros. Entretanto, os resultados dessa tentativa são bastante variados. Segundo Henriques ${ }^{6}$, as novas formas de modelos organizacionais exigem o desenvolvimento da comunicação estratégica para a mobilização social, que deve basear-se em princípios éticos que visam à ação de determinado coletivo para sua potencialização. Para isso, são necessárias a difusão das informações e a promoção da coletivização, em busca da conscientização e identificação dos sujeitos com o movimento. Objetiva-se a criação de uma cultura de comunidade em que se busca a modificação do processo da vida coletiva, no qual a comunicação se configura de forma que os indivíduos se produzam como sujeitos da coletividade ${ }^{7}$. Acredita-se que isso se faz necessário no momento em que a autogestão é "o conjunto de práticas sociais que se caracteriza pela natureza democrática das tomadas de decisão, o que propicia a autonomia de um coletivo" .

A importância desse debate evidencia-se, no Brasil e demais países da América Latina, pois como cita Peruzzo: “[...] os povos não têm a tradição [...] alcançar um grau de participação mais elevado é algo de difícil concretização" ${ }^{9}$. De acordo com os resultados obtidos na pesquisa de Veronese $^{10}$, mesmo 
tendo como princípios centrais a autogestão, a igualdade e a democracia, os EES podem produzir relações desiguais. Os trabalhadores que não participam da gestão direta do empreendimento, por vezes, assumem posições passivas perante a tomada de decisão. Veronese ${ }^{11}$ também demonstra que lideranças democráticas e integrativas podem estimular a participação e que isso é fator decisivo para o sucesso dos empreendimentos.

Os EES observados no período da pesquisa eram assessorados pelo Programa Tecnologias Sociais para Empreendimentos Solidários da Unisinos, na cidade de São Leopoldo, RS, Brasil. Observou-se o comportamento dos participantes perante o coletivo e individualmente, objetivando mapear como as condutas implicam o discurso e o processo de comunicação. De acordo com Gaskell ${ }^{12}$, estar atento a esses fatores direciona adequadamente a investigação e permite a melhor compreensão da realidade. O estudo realizado foi conduzido por meio de pesquisa qualitativa. As técnicas aplicadas foram: observação de campo, entrevista em profundidade ${ }^{13}$ e grupo focal ${ }^{14}$. Teve-se o cuidado de contatar trabalhadores que ocupavam, ou não, cargos de gestão nos empreendimentos. Para análise dos depoimentos optou-se pelo método análise de conteúdo, por meio da técnica análise da enunciação.

Sua principal característica é apoiar-se numa concepção de discurso como palavra em ato. [...] a análise da enunciação considera a produção da palavra um processo. [...] Isso é particularmente evidente nas entrevistas, cuja produção é ao mesmo tempo espontânea e constrangida pela situação ${ }^{15}$.

Procurou-se entender e representar as experiências relatadas "como um processo simbólico [...] na dinâmica ativa da vida social"16.

\section{A AUTOGESTÃO COMO RESULTADO DA PARTICIPAÇÃO COLETIVA IGUALITÁRIA}

"A gestão coletiva dos empreendimentos econômicos solidários depende da participação ativa e igualitária dos membros. Ou seja, depende da execução do poder compartilhado e do envolvimento dos trabalhadores nas tomadas de decisão." ${ }^{17}$ Como fatores importantes nas decisões coletivas, também estão o dissenso e o consenso. A partir dos pressupostos teóricos de Moscovici ${ }^{18}$, acredita-se que o consenso é a união de diferentes percepções, experiências e representações, a fim de encontrar uma resposta alternativa. Seguindo essa ideia, entende-se que a atuação passiva ou omissa entre os sujeitos enfraquece a decisão em conjunto. Moscovici também salienta que a confiabilidade extrema entre os sujeitos é fato problemático.

[...] foram precisamente elites [...] que prepararam decisões e fizeram escolhas de resultados verdadeiramente desastrosos. [...] Assim aconteceu durante a Segunda Guerra Mundial em face do ataque a Pearl Harbour. [...] A convicção da invulnerabilidade da frota americana era tão forte que eles deixaram que o abrigo se transformasse numa ratoeira ${ }^{19}$. sociais da liderança em empreendimentos econômicos solidários. Projeto de Pesquisa, 20072009. Não publicado.

11. Ibid.

12. GASKELL, George. Entrevistas individuais e grupais. In: BAUER, Martin W.; GASKELL, George (Ed.). Pesquisa qualitativa com texto: imagem e som. Um manual prático. Petrópolis, RJ: Vozes, 2002. p. 64-89.

13. DUARTE, Jorge. Entrevista em profundidade. In: DUARTE, Jorge; BARROS, Antônio (Org.). Métodos e técnicas de pesquisa em comunicação. 2. ed. São Paulo: Atlas, 2008. p. 72-82.

14. COSTA, Maria Eugênia Belczak. Grupo focal. In: DUARTE, op. cit., p. 180-192.

15. JÚNIOR, Wilson Corrêa da Fonseca. Análise de conteúdo. In: DUARTE, op. cit., p. 280-304.

16. JOVCHELOVITCH, Sandra. Os contextos do saber: representações, comunidade e cultura. Petrópolis, RJ: Vozes, 2008. p. 35.

17. MARTINS, Marina Rodrigues. Participação e comunicação como ações coletivas nos empreendimentos solidários. São Leopoldo: Unisinos. Caderno IHU, ano 6, n. 24, p. 1-21, ago. 2008. p. 8.

18. MOSCOVICl, Serge. Dissensões e consenso: uma teoria geral das decisões coletivas. Lisboa: Livros Horizonte, 1991.

19. Ibid., p. 16. 
comunicação \& educação • Ano XV • número 2 • maio/ago 2010

20. Ibid., p. 24.

21. JOVCHELOVITCH, op. cit.

22. SAMPAIO, Lia Regina Castaldi; NETO, Adolfo Braga. $O$ que é mediação de conflitos. São Paulo: Brasiliense, 2007.

23. Neste ensaio entende-se que o contentamento do coletivo se desenvolve em maior ou menor grau dentro de cada EES, nem sempre alcançando âmbito geral.

24. PERUZZO, op. cit.

25. OUTHWAIT E BOTTOMORE, 1996, apud D'AMICO, Ana. Comunicação e poder nas empresas familiares Dissertação (Mestrado em Comunicação Social). PUC/RS, 2004. p. 1. Não publicado.

26. ARANGUREM, J. L. Comunicação humana: uma sociologia da informação. Rio de Janeiro: Zahar; São Paulo: Edusp, 1975.

27. WATZLAWICK, Paul et al. Pragmática da comunicação humana: um estudo dos padrões, patologias e paradoxos da interação. 19. ed. São Paulo: Cultrix, 2008.

28. Ibid., 31.

29. PERUZZO, op. cit., p. 78.

30. JÚNIOR, Norval Baitello. Os meios da incomunicação: a outra face, demasiadamente humana, dos vínculos. In: JÚNIOR Norval Baitello; CONTRERA, Malena Segura; MENEZES, José Eugênio de O. (Org.). Os meios da incomunicação. São Paulo: Annablume/Cisc, 2005. p. 9-12.
Acredita-se que as diferentes opiniões podem propiciar troca de conhecimento, diversidade, oportunidade etc. "A discórdia, longe de ser um malogro ou uma resistência, é, no caso vertente, a alavanca mais preciosa da mudança" ${ }^{20}$. O autor argumenta que a percepção restrita do consenso, como simples eliminador de tensões, limita sua verdadeira função que é a proposta de mudança e inovação. Essa ideia pode ocasionar o desmantelamento dos grupos.

De acordo com Jovchelovitch ${ }^{21}$, o processo de comunicação entre sujeitos é essencial para a troca de diferentes representações sociais - saberes compartilhados, produzidos socialmente. O que colabora para o desenvolvimento do conhecimento geral e traz a possibilidade de evolução. Sampaio e Neto ${ }^{22}$ entendem que o diálogo funciona como mediador das informações numa conversa. A inteiração, a troca de informações e também de percepções promovem a negociação entre as diferentes pessoas. De acordo com os autores, a mediação visa à satisfação dos envolvidos ${ }^{23}$.

De acordo com Peruzzo ${ }^{24}$, o exercício do poder compartilhado propicia o surgimento do sujeito coletivo. No entanto, para atingir esse resultado cada participante precisa se autoperceber como corresponsável por ele e pelo coletivo. Confia-se que essas participações têm "a capacidade de produzir ou contribuir para resultados que afetem significativamente um outro ou outros" ${ }^{25}$.

Logo, entende-se que o processo de relação e troca social colabora para o exercício do poder compartilhado, por meio da participação ativa e igualitária.

\section{ALGUMAS FACES DA AÇÃO COMUNICATIVA}

A comunicação é o processo de transmitir e receber informação e depende de, pelo menos, quatro elementos, que são emissor, mensagem, meio e receptor. Essa ação é ativada, de maneira mais completa, através da linguagem, seja ela verbal, seja não verbal ${ }^{26}$. Watzlawick; Beavin e Jackson ${ }^{27}$ aprofundam o conceito argumentando que o comportamento tem valor de mensagem, pois ele se encontra em processo de interação com o meio. Ou seja, mesmo se mantendo sem verbalizar ou mover-se, o sujeito transmite sua mensagem. Os pesquisadores definem a comunicação "como uma unidade vagamente definida de comportamento" ${ }^{28}$. Entende-se, então, que a participação passiva e omissa implica decisões. Elas são caracterizadas pela posição de espectador conformado, adotada por um sujeito perante o grupo. Esse comportamento "se objetiza, se submete e simplesmente delega o poder à outra" ${ }^{29}$.

Júnior $^{30}$ denomina o processo de silêncio entre receptor e emissor como incomunicação. Configura-se quando existe a perda de vínculo entre sujeitos de um grupo, uma vez que o receptor reage em silêncio perante a mensagem do emissor, estabelecendo a não participação. Entende-se que a omissão ou a passividade em momentos de decisão nos EES propiciam a emancipação da incomunicação. Acredita-se que a repercussão dessa incompatibilidade pode gerar relações de conflito entre o grupo, problematizando a ação conjunta e ascendendo a desigualdade. 
A comunicação nos empreendimentos econômicos solidários • Marília e Marina

\section{A REALIDADE DISCURSADA E A TENTATIVA DE REPRESENTÁ-LA}

Apresentam-se, a seguir, as considerações feitas a partir dos discursos dos grupos focais e entrevistas individuais realizadas. Em sua amplitude, os depoimentos deixam transparecer saberes sobre a autogestão e alguns princípios para sua constituição na prática; mesmo assim, possuem subjetividade. A reflexão feita sobre os depoimentos busca representar o que os entrevistados entendem sobre a administração coletiva; como esse entendimento implica a participação e como o processo de comunicação acontece para beneficiar, ou não, a coletividade.

No primeiro grupo focal, realizado com um EES só de mulheres, do ramo de costura e artesanato, os depoimentos demonstraram saberes próprios de gestão coletiva, construídos na prática da economia solidária e da participação política ativa. Porém, observando discurso e comportamento identificou-se a disparidade entre ambos. Percebeu-se que a presença coletiva propiciou o entendimento mútuo entre as participantes. A troca de olhares e gestos favoreceu a concordância de opiniões. Algumas integrantes mantiveram-se passivas, apenas concordando ou até mesmo se omitindo.

Uma das fortes características do grupo é a função de mediador, assumida por suas integrantes, entre a comunidade e demais instituições sociais (escolas

\section{Figura 1}

Mapa conceitual elaborado após a análise da fala coletiva do primeiro grupo focal

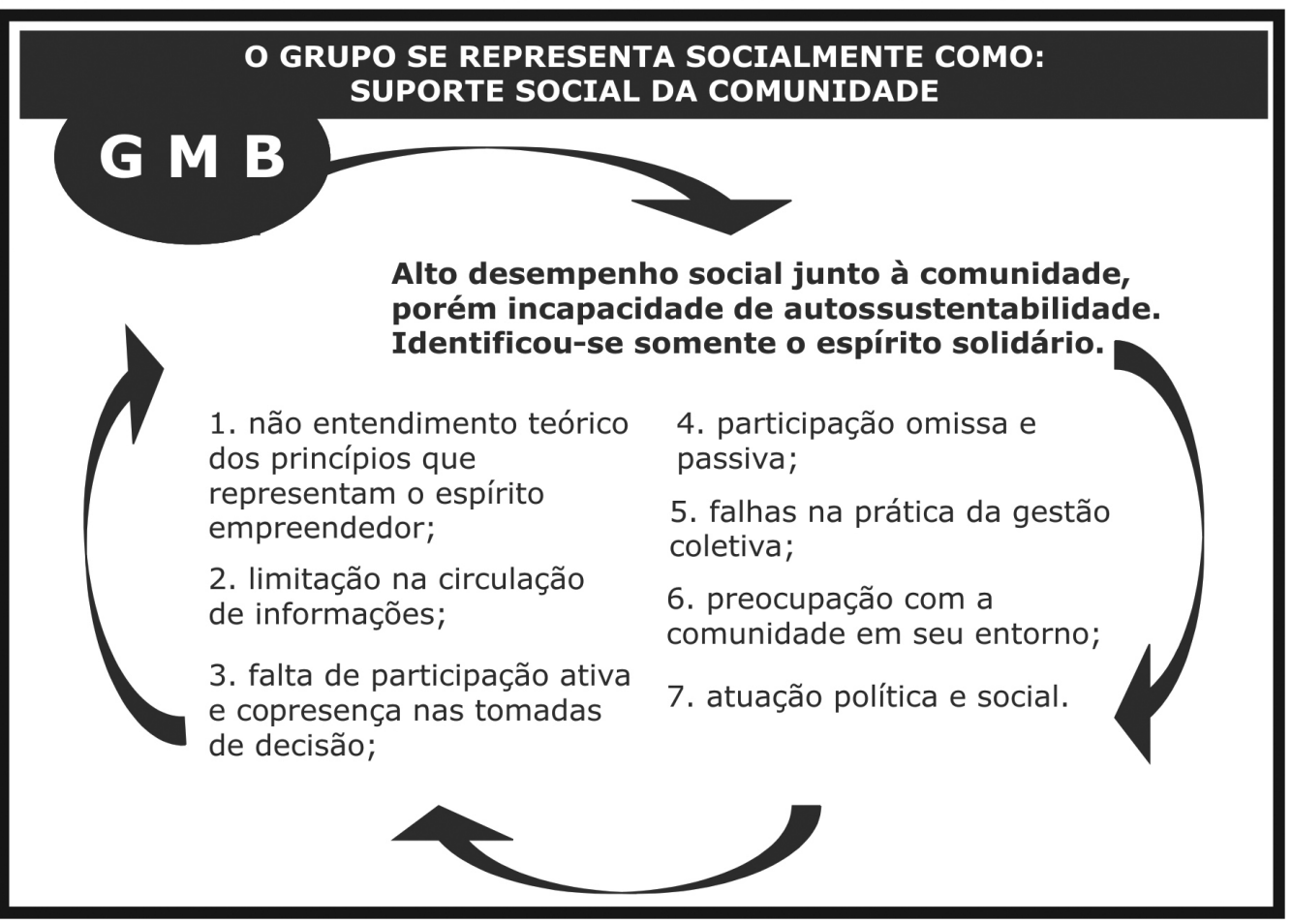


comunicação \& educação • Ano XV • número 2 • maio/ago 2010

31. Termo utilizado por ASSEBURG, op. cit., p. 16

32. Ibid., p. 42

33. Os trechos de depoimentos coletados durante um dos grupos focais realizados no período da pesquisa foram grafados com as letras maiúsculas para indicar a autoria da fala e nomes próprios para preservar a identidade dos entrevistados. do bairro, prefeitura etc.). O EES é distinguido pela autonomia feminina, potencializada pelo papel desenvolvido por suas participantes junto à comunidade. Elas têm o objetivo de trazer desenvolvimento para o local e, por meio da associação autogestionária, buscam a criação de uma frente de trabalho dentro da comunidade. Pertencer ao empreendimento significa ter a possibilidade de ser social, de estar entre e fazer parte de um coletivo. Possui uma mistura de identidades que favorece a troca de saberes e deveria proporcionar a evolução construtiva do grupo.

A observação sobre o depoimento coletivo representa o EES como um agente de mudanças e possibilidades, identificando-se o alto grau de espírito solidário $^{31}$. No entanto, aspectos ligados ao espírito empreendedor ${ }^{32}$ são citados com menos frequência no decorrer do discurso. $\mathrm{O}$ entendimento ou a prática de poder compartilhado e a participação ativa em momentos de decisão, considerados decisivos para a sustentabilidade do EES, aparecem de maneira inibida. As decisões são tomadas em encontros semanais com assuntos pré-agendados. Porém, a autogestão, como processo coletivo e participativo, é desfavorecida pela ausência das integrantes nos momentos de decisão, devido a problemas de saúde delas. Os exercícios de troca, aprendizado mútuo e autossustentação são restringidos pela incompatibilidade comunicativa, potencializada pela não presença em momentos de trabalho e decisão. $\mathrm{O}$ gerenciamento coletivo se demonstra falho em algumas horas e compreende-se que esse andamento prejudica e, em certas circunstâncias, pode invalidar a decisão coletiva.

Essas observações são aguçadas pelos discursos individuais, coletados nas entrevistas em profundidade; o grupo apresentou pouco domínio e entendimento sobre lideranças democráticas, autogestão e comunicação. A representação do EES acontece por meio das integrantes que mais frequentam o local comum ao grupo. Verificou-se que a posição passiva, geralmente, é adotada por trabalhadoras não envolvidas, diretamente, na gestão do empreendimento. Esse comportamento desfavorece a autogestão, colaborando com a participação omissa, geradora do poder autoritário, e potencializa o enfraquecimento do processo de comunicação, além do decrescimento do EES na perspectiva solidária.

A confiança entre as participantes é, claramente, outro aspecto que interfere na administração coletiva e na participação; além disso, o dissenso é entendido como conflito e não como possibilidade de inovação.

M: [...] às vezes quando eu sei que o grupo vai aprovar... Eu já aprovo ali também, tomo a decisão ali na hora... Por que a gente já sabe como é o grupo. [...] Por que até às vezes eu não posso ir. Elas tomam a decisão, depois... Amanhã eu vou, elas me passam, eu aceito! Por que eu vou discordar 33 ?

A comunicação acontece verbalmente, quando o grupo se encontra. Não foi estabelecido um processo de gerenciamento da informação, dificultando a troca de saberes e dados importantes para as decisões coletivas. $\mathrm{O}$ seguinte trecho demonstra o não conhecimento sobre assuntos do próprio grupo: "I: eu não sei te dizer agora de onde é, porque o dia que eles foram eu não estava presente". Acredita-se que esse comportamento impossibilita a participação ativa 
A comunicação nos empreendimentos econômicos solidários • Marília e Marina

da integrante nos momentos de decisão, o que fortalece a atuação passiva ou omissa perante o grupo e a incapacidade de administração coletiva.

As considerações seguintes são resultados da observação sobre o depoimento coletivo do segundo grupo focal realizado com integrantes de um EES do ramo de reciclagem de lixo urbano. A diferença de saberes sobre autogestão e trabalho associado entre o discurso anterior e o presente é, rapidamente, percebida. O exercício do poder compartilhado e a participação ativa são exercidos em maior grau nesse EES. Os trabalhadores envolvidos agem de forma igualitária, desempenhando papel fundamental para a sustentabilidade do empreendimento. Acredita-se que o entendimento da significação teórica dos princípios dos EES é fator-chave para que esses ocorram na prática. Esse coletivo demonstrou maior participação na discussão. A narrativa demonstrou a presença de conceitos apropriados de gestão coletiva, economia solidária e participação ativa, de maneira articulada.

O empreendimento é caracterizado pela mistura de gêneros. As posições de liderança são reconhecidas pelos integrantes, o que se confia favorecer a capacidade de autogerenciamento. O espirito empreendedor é identificado no discurso; o grupo visa à geração de trabalho e renda por meio da atividade associada, buscando democracia, cidadania e autossustentabilidade. A troca de conhecimentos é ação coletiva, sendo que todos os trabalhadores estão envolvidos com a produção e gerenciamento do empreendimento.

\section{Figura 2}

Mapa conceitual elaborado após a análise da fala coletiva do segundo grupo focal

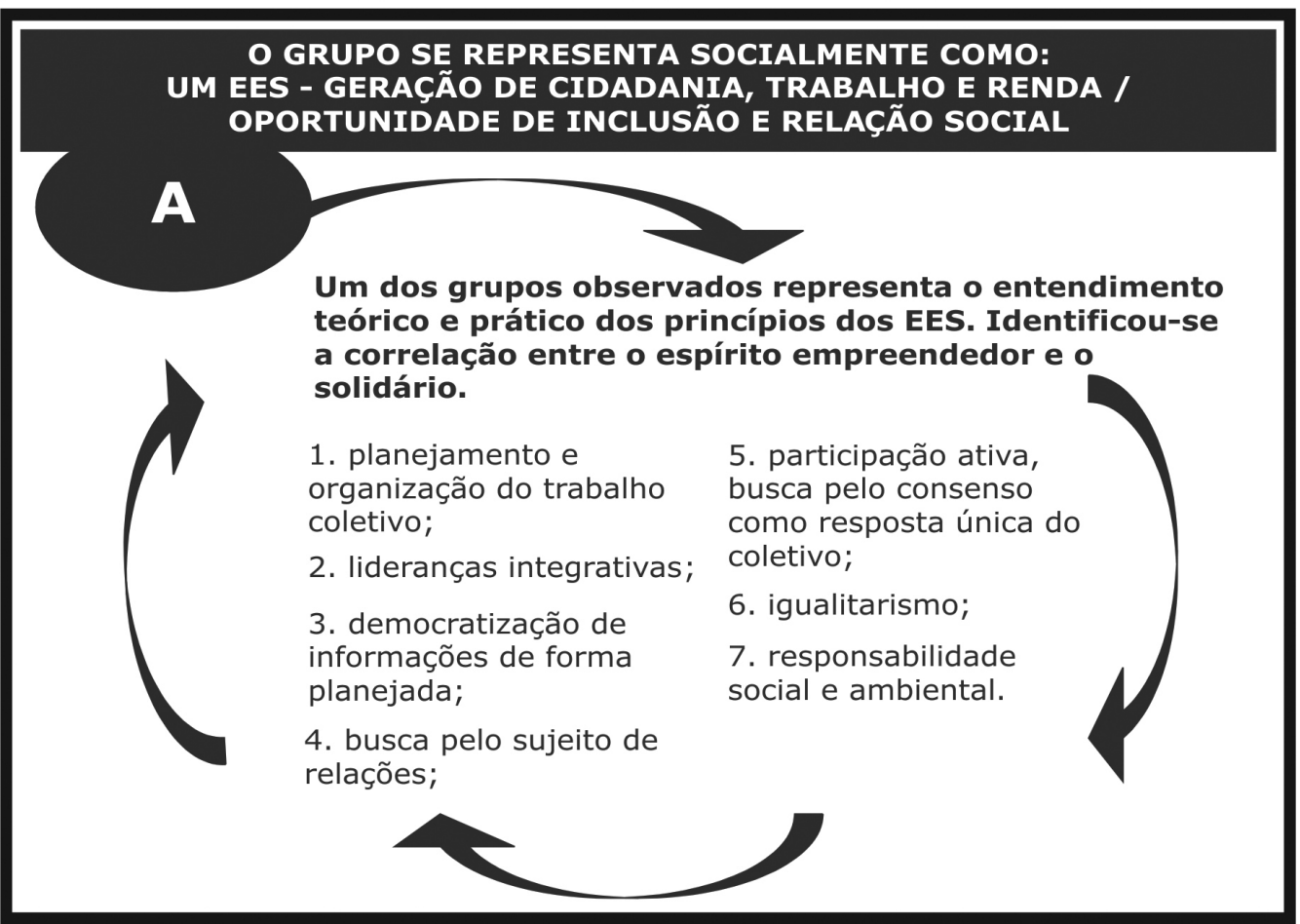


comunicação \& educação • Ano XV • número 2 • maio/ago 2010

As tomadas de decisão ocorrem em momentos presenciais e a democracia da informação é realizada em encontros diários, por meio da copresença na sede do grupo. A autogestão é vivenciada com seus benefícios e suas dificuldades: "C: Sempre tem algumas coisas boas e as coisas que tem que se resolver de ruim também. Quando tem alguma dificuldade ou outra. Nós tentamos sempre resolver... Com todo o coletivo". O planejamento das atividades possibilita a reorganização do trabalho, além de focar os resultados do EES em objetivos concretos e realizáveis, transformando a expectativa em experiência. O trabalho é subdividido e organizado para aperfeiçoar seu desenvolvimento. A organização e a difusão da informação colaboram para a democracia gestionária. O comportamento autônomo é perceptível nos integrantes, facilitando uma articulação política e social junto à sociedade. A decisão coletiva é embasada nas opiniões dos envolvidos. A subdivisão dos grupos de trabalho e a nomeação de coordenações buscam fomentar a participação ativa dos associados e o poder compartilhado. A troca de funções subsidia a autonomia e o conhecimento sobre as atividades do EES, capacitando cada integrante para a administração coletiva.

O espirito solidário também é identificado através do desenvolvimento de ações que visam ao desenvolvimento social do grupo e de comunidades do entorno, junto ao cuidado ambiental. A ação de conscientização é pensada de forma estratégica, a fim de atender a expectativas de autossustentabilidade do EES com as de meio ambiente. Esse coletivo desenvolve a conscientização de seus trabalhadores, os quais buscam repassar para a comunidade no exercício diário. Identifica-se, então, a amplitude do processo de comunicação nesse EES e a capacidade formativa dentro desse coletivo.

A apreensão de novos saberes oportuniza novas práticas e nova vida. A vida coletiva traz cidadania, direitos e deveres, bem como a possibilidade de crescer com os companheiros e resgatar a dignidade por meio do trabalho autogestionário. A autonomia fornece a redescoberta da identidade em cada integrante do grupo, pois em sua maior parte se percebe como ator contínuo da vida coletiva. Nota-se que o entendimento dos princípios das organizações solidárias e a força conjunta possibilitam transformar, muitas vezes, conflitos em oportunidades na busca pela ampliação do conhecimento dos envolvidos.

\section{CONSIDERAÇÕES FINAIS}

A análise identificou a diferença entre as realidades dos empreendimentos entrevistados. Enquanto um percebe e exercita, de forma mais desenvolvida, a gestão coletiva, conhecendo seus benefícios, dificuldades e contradições, outro apresenta maior distanciamento dessa experimentação. Em outras palavras, a prática da autogestão e demais princípios dos EES são claramente percebidos em seus diferentes graus de execução, em cada empreendimento estudado.

A democratização da informação comprova-se potencializadora da participação ativa nos momentos de decisão. A copresença também é fator importante para o exercício do poder compartilhado. As decisões são debatidas e acordadas 
A comunicação nos empreendimentos econômicos solidários • Marília e Marina

mais proveitosamente nas reuniões presenciais. Além de que, quando esses encontros tornam-se diários, possibilitam mais contato do trabalhador com os companheiros e o empreendimento, fazendo-os se perceberem na realidade do coletivo. Verifica-se que a incomunicação é fortalecida pela participação omissa e passiva de alguns integrantes, comportamento que enfraquece a decisão coletiva e acaba por distanciar a prática dos princípios autogestionários. $\mathrm{O}$ reconhecimento e o entendimento das vias democráticas que guiam as organizações solidárias favorecem a experiência. Mesmo demonstrando a dificuldade de unir os espíritos solidário e empreendedor, a ação mostra-se fundamental para geração de autonomia e crescimento contínuo proposto pelos EES.

A presença e relação estabelecida entre os trabalhadores são fortalecidas pela união e troca de diferentes saberes, através de cada relato. A interação instiga novas expectativas e a busca de novas alternativas. $\mathrm{O}$ conhecimento amplia os objetivos e fornece subsídios para argumentação, trazendo mais chances de administração coletiva participativa. A disseminação constante da informação proporciona o entendimento da realidade dos EES por seus trabalhadores, o que facilita o debate em momentos de decisão e consenso do grupo, como resultado evolutivo.

Logo, o entendimento dos princípios que guiam os EES, pelos envolvidos, favorece o processo de autogestão, o qual se constata ser influenciado, diretamente, pelo processo de comunicação e participação ativa. Ou seja, o desenvolvimento da autogestão se demonstra um circuito de ações correlacionadas, interligadas pela comunicação estabelecida pelos sujeitos envolvidos e potencializada pela copresença. Nessa perspectiva o processo de comunicação entendido como ferramenta educacional possibilita o desenvolvimento da capacidade intelectual dos trabalhadores, proporcionando a apreensão, compreensão e adaptação de cada um na realidade coletiva.

\section{REFERÊNCIAS BIBLIOGRÁFICAS}

ALBUQUERQUE, Paulo Peixoto de. Autogestão. In: CATTANI, Antonio David (Org.). A outra economia. Porto Alegre: Veraz Editores, 2003.

ARANGUREM, J. L. Comunicação humana: uma sociologia da informação. Rio de Janeiro: Zahar; São Paulo: Edusp, 1975.

ASSEBURG, Hans Benno; OGANDO, Cláudio Barcelos. Cartilha da Economia Solidária: subsídio informativo. A Economia Solidária no Rio Grande do Sul: resultados do primeiro mapeamento nacional. A perspectiva dos Direitos Humanos. San José/Costa Rica: Unesco, 2006.

COSTA, Maria Eugênia Belczak. Grupo focal. In: DUARTE, Jorge; BARROS, Antônio (Org.). Métodos e técnicas de pesquisa em comunicação. 2. ed. São Paulo: Atlas, 2008.

DUARTE, Jorge. Entrevista em profundidade. In: DUARTE, Jorge; BARROS, Antônio (Org.). Métodos e técnicas de pesquisa em comunicação. 2. ed. São Paulo: Atlas, 2008. 
comunicação \& educação • Ano XV • número 2 • maio/ago 2010

GASKELL, George. Entrevistas individuais e grupais. In: BAUER, Martin W.; GASKELL, George (Ed.). Pesquisa qualitativa com texto: imagem e som. Um manual prático. Petrópolis, RJ: Vozes, 2002.

HENRIQUES, Márcio Simeone et al. Relações Públicas em projetos de mobilização social: funções e características. In: HENRIQUES, Márcio Simeone (Org.). Comunicação e estratégias de mobilização social. 2. ed. São Paulo: Autêntica, 2004.

JOVCHELOVITCH, Sandra. Os contextos do saber: representações, comunidade e cultura. Petrópolis, RJ: Vozes, 2008.

JÚNIOR, Norval Baitello. Os meios da incomunicação: a outra face, demasiadamente humana, dos vínculos. In: JÚNIOR, Norval Baitello; CONTRERA, Malena Segura; MENEZES, José Eugênio de O. (Org.). Os meios da incomunicação. São Paulo: Annablume/Cisc, 2005.

JÚNIOR, Wilson Corrêa da Fonseca. Análise de conteúdo. In: DUARTE, Jorge; BARROS, Antônio (Org.). Métodos e técnicas de pesquisa em comunicação. 2. ed. São Paulo: Atlas, 2008.

MARTINS, Marina Rodrigues. Participação e comunicação como ações coletivas nos empreendimentos solidários. São Leopoldo: Unisinos. Caderno IHU, ano 6, n. 24 ago. 2008.

As relações públicas e a economia solidária: um compromisso para transformação social. Monografia apresentada para o Curso de Comunicação Social - Habilitação em Relações Públicas, na Universidade do Vale do Rio dos Sinos, 2007. Não publicado.

MOSCOVICI, Serge. Dissensões e consenso: uma teoria geral das decisões coletivas. Lisboa: Livros Horizonte, 1991.

OUTHWAIT; BOTTOMORE, 1996, apud D'AMICO, Ana. Comunicação e poder nas empresas familiares. Dissertação (Mestrado em Comunicação Social). PUC/ RS, 2004. Não publicado.

PERUZZO, Cicília Maria Krohling. Comunicação nos movimentos populares: a participação na construção da cidadania. Petrópolis, RJ: Vozes, 1998.

SAMPAIO, Lia Regina Castaldi; NETO, Adolfo Braga. O que é mediação de conflitos. São Paulo: Brasiliense, 2007.

VERONESE, Marília Veríssimo. Representações sociais da liderança em empreendimentos econômicos solidários. Projeto de Pesquisa 2007-2009. Não publicado.

VIEIRA, Roberto Fonseca. Relações Públicas: opção pelo cidadão. Rio de Janeiro: Mauad, 2002.

WATZLAWICK, Paul et al. Pragmática da comunicação humana: um estudo dos padrões, patologias e paradoxos da interação. 19. ed. São Paulo: Cultrix, 2008. 